\title{
ÚNG DỤNG SẢN PHẨM MÔ HÌNH DỤ๋ BÁO THÒ̀I TIẾT PHÂN GIẢI CAO WRF-ARW TRONG DỬ BÁO QUỸ ĐẠO VÀ BÀI TOÁN ĐỊNH HƯỚNG TĂNG CƯỜNG QUAN TRĂC BÓNG THÁM KHÔNG
}

\author{
Phạm Hồng Quang ${ }^{1}$, Dư Đức Tiến², Phạm Hồng Công¹, \\ Mai Khánh Hưng², Đặng Đình Quân ${ }^{2}$
}

Tóm tắt: Bài báo trình bày một số kết quả sủ dụng trường dụ báo tù mô hình khu vực phân giải cao WRF-ARW làm đầu vào cho mô hình mô phỏng đường đi của bóng thám không, nhằm muc đích định hướng vị trí cần quan trắc cho trước, ví dụ nhu ngoài Biển Đông hay các vùng núi chưa có dũ liệu quan trắc. Với trường dụ báo khí tương cho truớc, mô hình mô phỏng đường đi (trajectory) cho phép truy ngược (backward) để xác định điểm thả bóng thám không ưng với vị trí cần quan trắc cho trước. Các kết quả thư nghiệm ban đầu đối với mode dụ báo xuôi (forward) của mô hình mô phỏng đường đi của nghiên cưu trong tháng 4 năm 2019 khi so sánh cu thể với quỹ đạo của bóng thám không quan trắc của Đài Khí tương cao không. Bên cạnh đó một số đánh giá bổ sung với kết quả dư báo tù một mô hình mô phỏng đường đi khác (CUSF, Trưòng đại học Cambridge, Anh Quốc) được thực hiện cho thấy tính phù hợp của mô hình tính toán đường đi trong nghiên cứu và làm tiền đề cho các bài toán định hương thả bóng thám không tăng cương đến các vị trí định trước trong nhũng nghiên cứu tiếp theo.

Từ khóa: Mô hình WRF-ARW, mô hình hương, quan trắc thám không.

Ban Biên tập nhận bài: 12/03/2019 Ngày phản biện xong: 20/5/2019 Ngày đăng bài: 25/05/2019

\section{Mở đầu}

Hiện nay công nghệ khinh khí cầu với khả năng bay trên tầng bình lưu và tích hợp trạm thu phát thông tin cho phép ứng dụng trong các vấn đề gồm giám sát, dẫn đường, tìm kiếm cứu hộ và đo đạc thông số vật lý môi trường tầng khí quyển. Mô hình tích hợp khinh khí cầu với các mô hình tàu lượn, dù hoặc phương tiện bay không người lái hay máy bay không người lái (UAV - Unmanned aerial vehicle) và có khả năng điều khiển để kéo dài thời gian hoạt động trên không trung được là HAPS - High Altitude Pseudo-Satellites hay là một dạng trạm tựa vệ tinh, thường là một máy bay không người lái được đặt ở độ cao từ 20 đến $50 \mathrm{~km}$ và tại một

${ }^{1}$ Trung tâm Tin họ và Tính toán, Viện Hàn lâm Khoa học và Công nghệ Việt Nam

${ }^{2}$ Trung tâm Dự báo khi tượng thủy văn quốc gia Email:duductien@gmail.com điểm cố định so với Trái đất) và định hướng hoạt động, có thể thu hồi sau khi hoàn thành các đo đạc $[3,6]$.

Với vấn đề nêu trên, việc ứng dung mô phỏng và dự báo hoạt động của các luồng khí trong tầng bình lưu, làm đầu vào việc dự báo hành trình của bóng, tìm vị trí thả bóng và điểu khiển duy trì HAPS trong thời gian dài là cần thiết. Trong nghiên cứu này sẽ trình bày một số kết quả sử dụng trường dự báo từ mô hình khu vực phân giải cao WRF-ARW làm đầu vào cho mô hình mô phỏng đường đi của bóng thám không và phục vụ mục đích định hướng vị trí cần quan trắc cho trước. Sử dụng trường dự báo từ mô hình khí tượng cho trước, mô hình mô phỏng đường đi (trajectory) được giới thiệu trong phần II của bài báo. Một số kết quả ban đầu được đưa ra cung các so sánh với quỹ đạo thực tế được đưa ra trong phần III. Bên cạnh đó, quỹ đạo dự báo 


\section{BÀI BÁO KHOA HỌC}

cũng được đánh giá chéo với một mô hình mô phỏng đường đi của bóng trong nghiên cứu so với thực tế.

\section{Thiết kế thí nghiệm}

\subsection{Mô hình số trị khu vục WRF-ARW}

Trong nghiên cứu sử dụng hệ thống mô hình khu vực WRF với nhân động lực ARW phiên bản 3.9.1.1 do Trung tâm dự báo môi trường quốc gia Mỹ (NCEP) phát triển (gọi tắt là WRF$\mathrm{ARW})$. Mô hình WRF-ARW cũng được thử nghiệm và áp dụng trong nghiệp vụ tại Việt Nam trong các lĩnh vực dự báo thời tiết và dự báo bão. Mô hình WRF-ARW được nghiên cứu và áp dụng phổ biến tại Việt Nam những năm vừa qua, các công trình điển hình có thể kể đến gồm trong nghiên cứu dự báo thời tiết và bão [1] hay trong việc áp dụng và dự báo tổ hợp [7]. Chi tiết hơn về mô hình WRF-ARW có thể tham khảo trong $[2,4]$.

Thử nghiệm thiết lập hai lưới tính $15 \mathrm{~km}$ và $5 \mathrm{~km}$ cho mô hình WRF-ARW, số 90 mực thẳng đứng và dự báo đến hạn $72 \mathrm{~h}$. Độ cao nhất của mô hình xấp xỉ $40 \mathrm{~km}$. Đối với dự báo chuẩn (control), các lựa chọn vật lý cho mô hình WRFARW bao gồm: sơ đồ Kain-Fritsch (KF) cho tham số hóa đối lưu, sơ đồ bức xạ sóng ngắn Goddard, sơ đồ tham số hóa lớp biên của MellorYamada-Janjic (MYJ), sơ đồ vi vật lý mây khép kín 6 bậc WSM6 và sơ đồ rối bế mặt là Janjic Eta. Trường gió dự báo từ mô hình WRF-ARW sẽ được sử dụng làm đầu vào cho mô hình mô phỏng đường đi (trajectory) trong mục 2.2.

\subsection{Mô hình mô phỏng đường đi}

Theo Stohl [5] quỹ đạo của một phân tử khí (ứng với giá thiết tương ứng khi áp cho Bóng thả) được miêu tả bởi phương trình sai phân:

$$
\frac{d X}{d t}=v(X, t)
$$

trong đó $\mathrm{X}$ kí hiệu ứng với vector vị trí của phân tử khí, $\mathrm{v}$ là trường gió và t là thời gian. Viết lại dưới dạng tích phân cho biến $\mathrm{X}$

$$
X(t)=X\left(t_{0}\right)+\int_{t_{0}}^{t} v(X, t) d t
$$

Phương trình này có thể giải lặp sử dụng gió trung bình giữa điểm $\mathrm{X}\left(\mathrm{t}_{0}\right)$ và điểm đến tiếp $\mathrm{X}\left(\mathrm{t}_{1}\right)$ theo công thức cho bước lặp thứ nhất ứng với trường gió tại điểm $X\left(\mathrm{t}_{0}\right)$ :

$$
X^{1}\left(t_{1}\right)=X\left(t_{0}\right)+v X\left(t_{0}\right) \Delta t
$$

Tại bước lặp thứ i được tính từ giá trị ở thứ i-1 theo công thức

$X^{i}\left(t_{1}\right)=X\left(t_{0}\right)+\frac{1}{2}\left[v X\left(t_{0}\right)+v X^{i-1}\left(t_{1}\right)\right] \Delta t$

\subsection{Số liệu điều kiện biên, quan trắc và các trường hợp thử nghiệm}

Trong nghiên cứu, số liệu dự báo toàn cầu GFS (Mỹ) với độ phân giải 50km x 50km được sử dụng làm điều kiện ban đầu và điều kiện biên theo thời gian cho mô hình WRF-ARW và được cập nhật 3 tiếng một lần. Các kết quả dự báo gió chi tiết 10 phút một lần của mô hình WRF-ARW của lưới dự báo $5 \mathrm{~km} x 5 \mathrm{~km}$ tại các mực từ bề mặt đến độ cao xấp xỉ $40 \mathrm{~km}$ được sử dụng làm đầu vào cho mô hình dự báo quỹ đạo (mục 2.1).

Để so sánh kết quả dự báo quỹ đạo, số liệu quỹ đạo bóng thám không sử dụng trong quan trắc cao không [9] được thu thập cho các trường hợp thử nghiệm ốp $00 Z$ và $12 Z$ từ ngày 01/04/2019 đến 31/04/2019. Đầu vào cho mô hình quỹ đạo được lấy từ trường dự báo gió của mô hình WRF-ARW dự báo 12 tiếng trước đó (hình 1).

Quỹ đạo của bóng thám không được sử dụng như là quan trắc để so sánh với quỹ đạo mô phỏng tính toán trong mục 2.2. Ngoài ra quỹ đạo tính toán cũng được so sánh với mô hình dự báo khá phổ biến Cambridge University Spaceflight (CUSF) Landing Predictor phiên bản 2.5 của Trường đại học Cambridge của nước Anh (tham khảo trên trang web https://predict.habhub.org). 


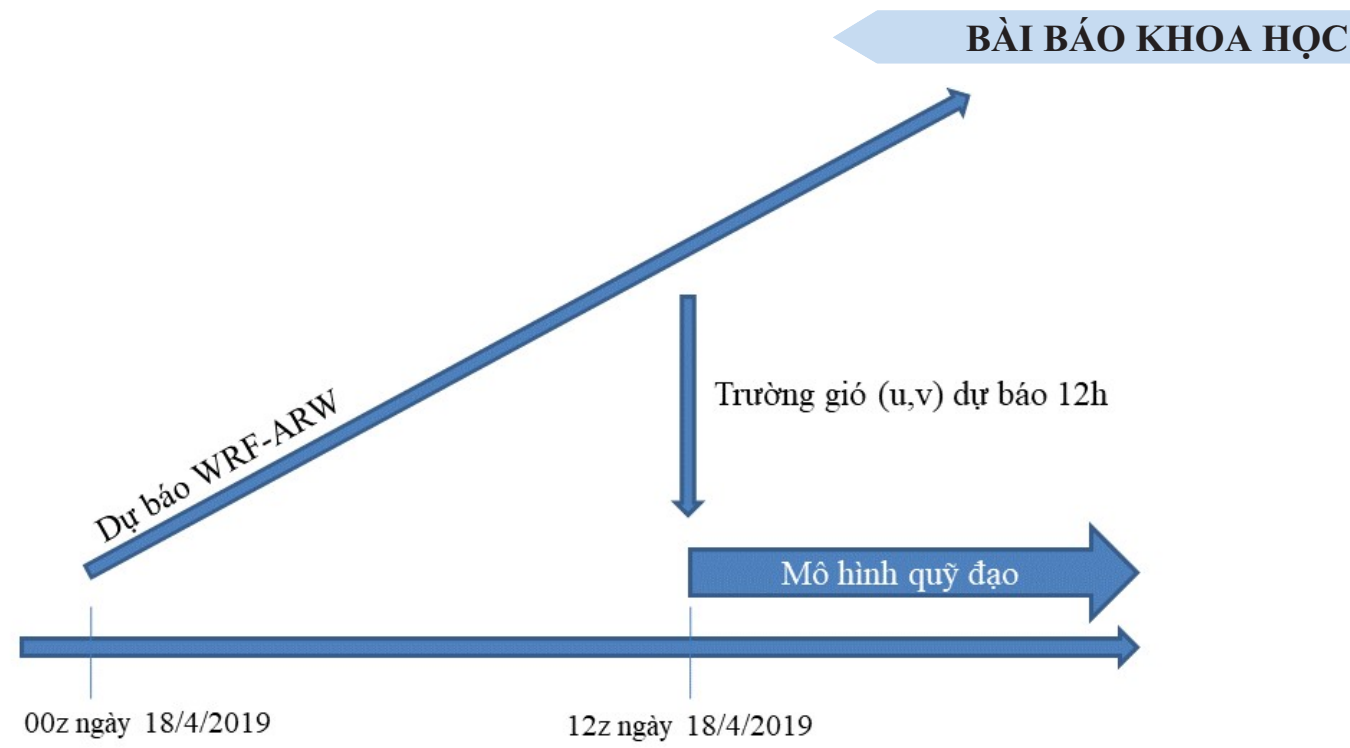

Hình 1. Minh họa việc sử dụng dụ báo tù mô hình WRF-ARW làm đầu vào cho mô hình

\section{3. Đánh giá kết quả}

Hình 2 minh họa trường gió của mô hình toàn cầu GFS (điều kiện biên) và gió chi tiết từ mô hình khu vực WRF-ARW tại các mực cơ bản $500 \mathrm{hPa}$ và $200 \mathrm{hPa}$. Từ số liệu dự báo trường gió của GFS (tại ốp 00z trong ngày 18/04/2019) cho thấy dòng gió đi qua khu vực miền Bắc nước ta (bao gồm Hà Nội) ở mực 500hPa có hướng thịnh hành là hướng Tây, với vận tốc từ $15-20 \mathrm{~m} / \mathrm{s}$. Ở mực 200hPa, hướng gió thịnh hành qua khu vực

(a)

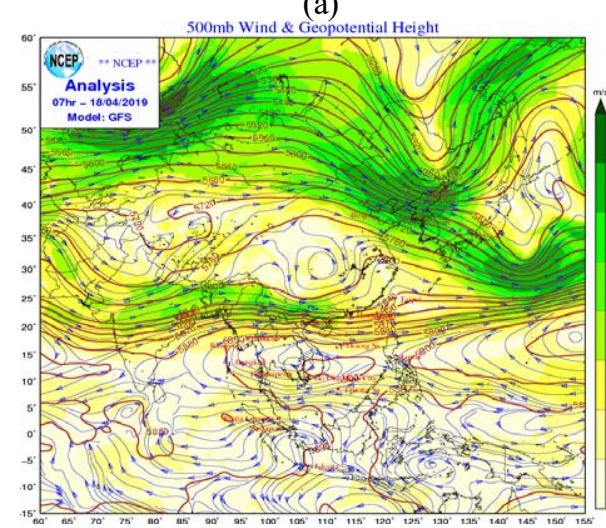

(c)

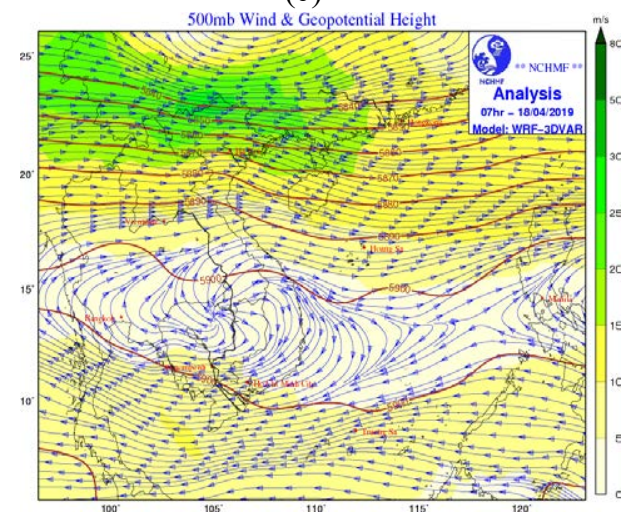

này vẫn là hướng Tây, vận tốc gió qua khu vực từ $20-30 \mathrm{~m} / \mathrm{s}$. Với số liệu trường gió chi tiết WRF - ARW, trên mực $500 \mathrm{hPa}$ và mực $200 \mathrm{hPa}$, hướng gió thịnh hành cũng là gió Tây, vận tốc gió khi đi qua khu vực đang xét lần lượt là 15 $20 \mathrm{~m} / \mathrm{s}$ và $20-30 \mathrm{~m} / \mathrm{s}$. Với điều kiện gió nền trong ngày 18/04/2019, bóng thả từ khu vực Hà Nội về cơ bản sẽ có quĩ đạo đi lên rồi di chuyển từ Tây sang Đông tại các mực tầng cao hơn $5 \mathrm{~km}$.

(b)

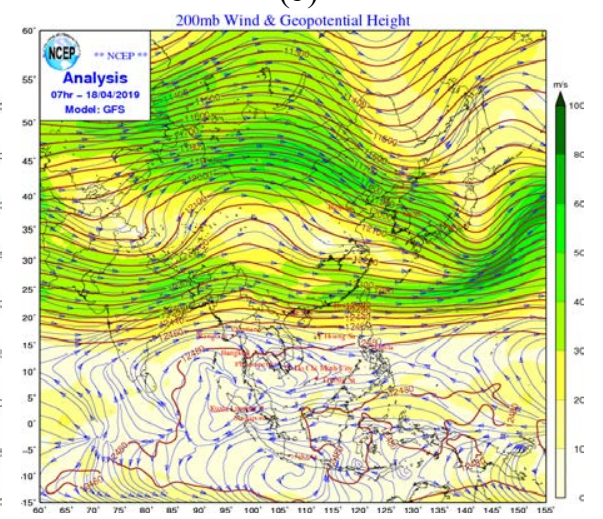

(d)

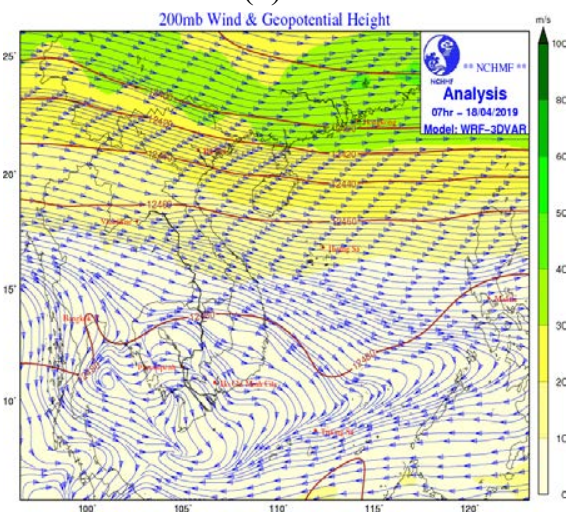

Hình 2. Minh họa truờng gió của GFS $(a, b)$ và gió chi tiết tù̀ WRF-ARW $(c, d)$ lần luợt ở các tầng 500hPa và 200hPa lúc 00z ngày 18/04/2019 
Tiếp theo, đánh giá từ số liệu quỹ đạo từ bóng thám không, số liệu dự báo và số liệu từ mô hình CUSF được thống kê dưới bảng 1 và hình 3 cho thấy: về cơ bản, theo thời gian, số liệu dự báo và số liệu CUSF đều cho khoảng thời gian bóng bay từ mực $500 \mathrm{hPa}$ lên đến mực $200 \mathrm{hPa}$ là trong 22 phút, nhiều hơn số liệu từ quỹ đạo của bóng thám không là 3 phút; tức với số liệu quỹ đạo của bóng, từ mực $500 \mathrm{hPa}$ đến mực $200 \mathrm{hPa}$, bóng bay trong khoảng 19 phút. So với số liệu quỹ đạo của bóng, thời gian để bóng lên được đến mực 500hPa của số liệu dự báo trễ hơn 12 phút, còn số liệu CUSF là 13 phút; tương tự với mực $200 \mathrm{hPa}$, độ trễ lần lượt là khoảng 15 phút và 16 phút. Về tọa độ của bóng thám không, số liệu quỹ đạo bóng, số liệu dự báo và số liệu từ mô hình CUSF đều cho tọa độ khá tương đồng. Các số liệu dự báo đều cho chênh lệch với quỹ đạo của bóng là 0,01 độ ứng với sai số khoảng dưới
$1 \mathrm{~km}$. Riêng số liệu dự báo, tại mực 500hPa cho tọa độ gần như trùng với tọa độ thực của bóng. Tại mực $200 \mathrm{hPa}$, số liệu dự báo có sai số 0,06 độ so với quỹ đạo của bóng. Về độ cao bóng, số liệu dự báo có kết quả gần như trùng với quỹ đạo bóng. Trong khi đó, số liệu từ mô hình CUFS cho độ cao bóng thấp hơn 100m so với quỹ đạo thực của bóng. Về quỹ đạo chung của bóng tính từ mực $1000 \mathrm{hPa}$ đến mực $10 \mathrm{hPa}$, cả hai số liệu dự báo đều cho quỹ đạo tương đồng với quỹ đạo thực tế của bóng. Điều này được thể hiện thông qua biểu đồ và đường bay của bóng trên hình 3 và hình 4,5 ; trong đó, các vòng cung ứng với các mực độ cao khác nhau (đơn vị $m$ ) và các hình quỹ đạo theo chiều ngang của bóng thám không và quỹ đạo dự báo. Có thể thấy, số liệu dự báo và số liệu từ CUSF luôn cho quỹ đạo rộng hơn khá nhiều so với số liệu thực tế và chỉ gần đúng ở các mực khí áp tầng thấp.

Bảng 1. Thông số chi tiết dụ báo vị trí bóng tù quan trắc cao không, mô hình dụ báo quỹ đạo sủ dụng điều kiện biên tì̀ mô hình WRF-ARW và dụ báo tù mô hình CUSF

\begin{tabular}{|c|c|c|c|c|c|c|c|c|c|c|}
\hline $\begin{array}{l}\text { Thời } \\
\text { gian }\end{array}$ & $\begin{array}{c}\text { Kinh } \\
\text { độ bóng } \\
\text { Cao } \\
\text { không }\end{array}$ & $\begin{array}{c}\text { Vĩ độ } \\
\text { bóng } \\
\text { Cao } \\
\text { không }\end{array}$ & $\begin{array}{c}\text { Độ cao } \\
\text { bóng Cao } \\
\text { không } \\
\text { (m) }\end{array}$ & $\begin{array}{c}\text { Kinh } \\
\text { độ bóng } \\
\text { Dự báo }\end{array}$ & $\begin{array}{c}\text { Vĩ độ } \\
\text { bóng } \\
\text { Dự báo }\end{array}$ & $\begin{array}{c}\text { Độ cao } \\
\text { bóng } \\
\text { Dự báo } \\
\text { (m) }\end{array}$ & $\begin{array}{c}\text { Kinh } \\
\text { độ } \\
\text { bóng } \\
\text { CUSF }\end{array}$ & $\begin{array}{c}\text { Vĩ độ } \\
\text { bóng } \\
\text { CUSF }\end{array}$ & $\begin{array}{c}\text { Độ cao } \\
\text { bóng } \\
\text { CUSF } \\
\text { (m) }\end{array}$ & $\begin{array}{l}\text { Gió dự } \\
\text { báo từ } \\
\text { WRF } \\
(\mathrm{m} / \mathrm{s})\end{array}$ \\
\hline \multicolumn{11}{|l|}{ 2019-04- } \\
\hline 18 & 105,941 & 21,013 & 5868,207 & 105,833 & 21,030 & 2300 & 105,824 & 21,039 & 1940 & \\
\hline \multicolumn{11}{|l|}{$00: 07: 36$} \\
\hline \multicolumn{11}{|l|}{ 2019-04- } \\
\hline 18 & 106,082 & 21,048 & 10242,470 & 105,933 & 21,013 & 5850 & 105,925 & 21,027 & 5660 & $15-20$ \\
\hline \multicolumn{11}{|l|}{$00: 19: 30$} \\
\hline \multicolumn{11}{|l|}{ 2019-04- } \\
\hline 18 & 106,088 & 21,050 & 11167,450 & 105,939 & 21,013 & 6050 & 105,932 & 21,027 & 5750 & \\
\hline \multicolumn{11}{|l|}{$00: 20: 10$} \\
\hline \multicolumn{11}{|l|}{ 2019-04- } \\
\hline 18 & 106,212 & 21,031 & 12440,932 & 105,999 & 21,022 & 8000 & 105,997 & 21,036 & 7505 & \\
\hline \multicolumn{11}{|l|}{$00: 26: 42$} \\
\hline \multicolumn{11}{|l|}{ 2019-04- } \\
\hline 18 & 106,322 & 20,964 & 19855,500 & 106,211 & 21,037 & 12450 & 106,218 & 21,047 & 11550 & $20-30$ \\
\hline \multicolumn{11}{|l|}{$00: 41: 30$} \\
\hline \multicolumn{11}{|l|}{ 2019-04- } \\
\hline 18 & 106,311 & 20,958 & 17811,728 & 106,226 & 21,032 & 12800 & 106,243 & 21,042 & 12500 & \\
\hline $00: 42: 40$ & & & & & & & & & & \\
\hline
\end{tabular}



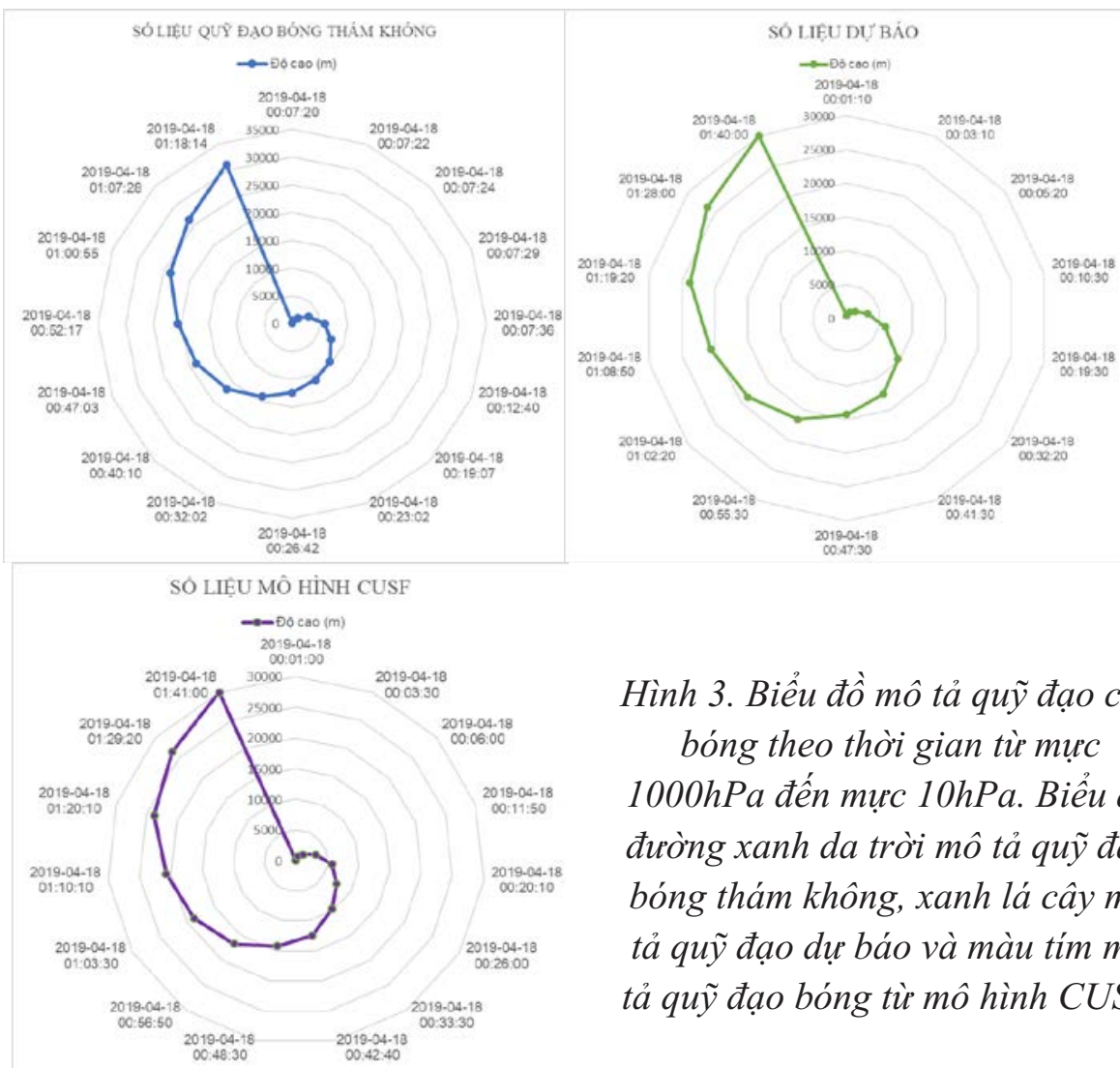

Hình 3. Biểu đồ mô tả quỹ đạo của bóng theo thờ gian tù muc 1000hPa đến mưc 10hPa. Biểu đồ đưòng xanh da trời mô tả quỹ đạo bóng thám không, xanh lá cây mô tả quỹ đạo dụ báo và màu tím mô tả quỹ đạo bóng tù mô hình CUSF.

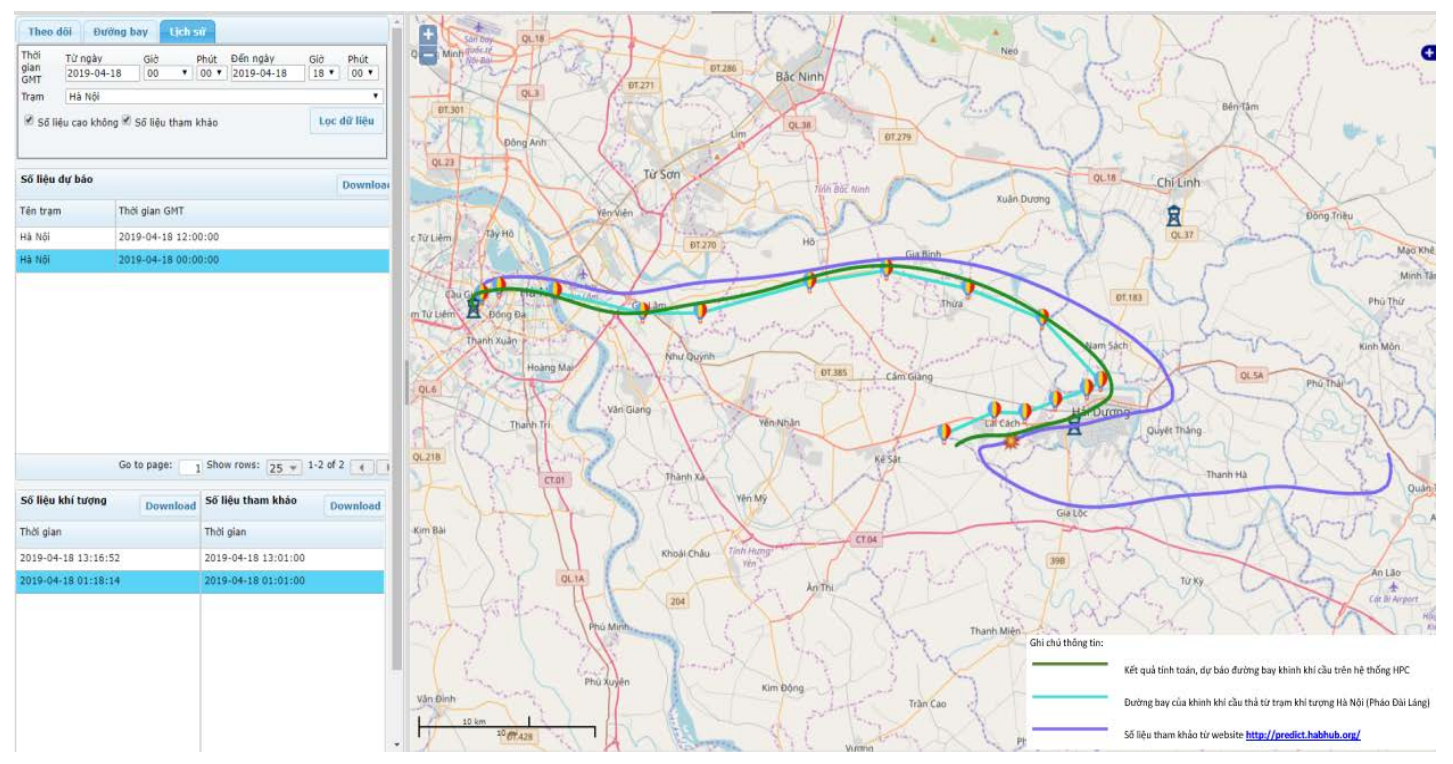

Hình 4. Số liệu dụ báo ngày 18/04/2019 phiên 00UTC. Ki hiệu hình khinh khí cầu và đường xanh nhạt ưng với vị trí của bóng thám không, đường màu xanh thẫm ứng với quỹ đạo dụ báo và đường màu tím ứng với quỹ đạo dụ báo tù̀ CUSF. 


\section{BÀI BÁO KHOA HỌC}

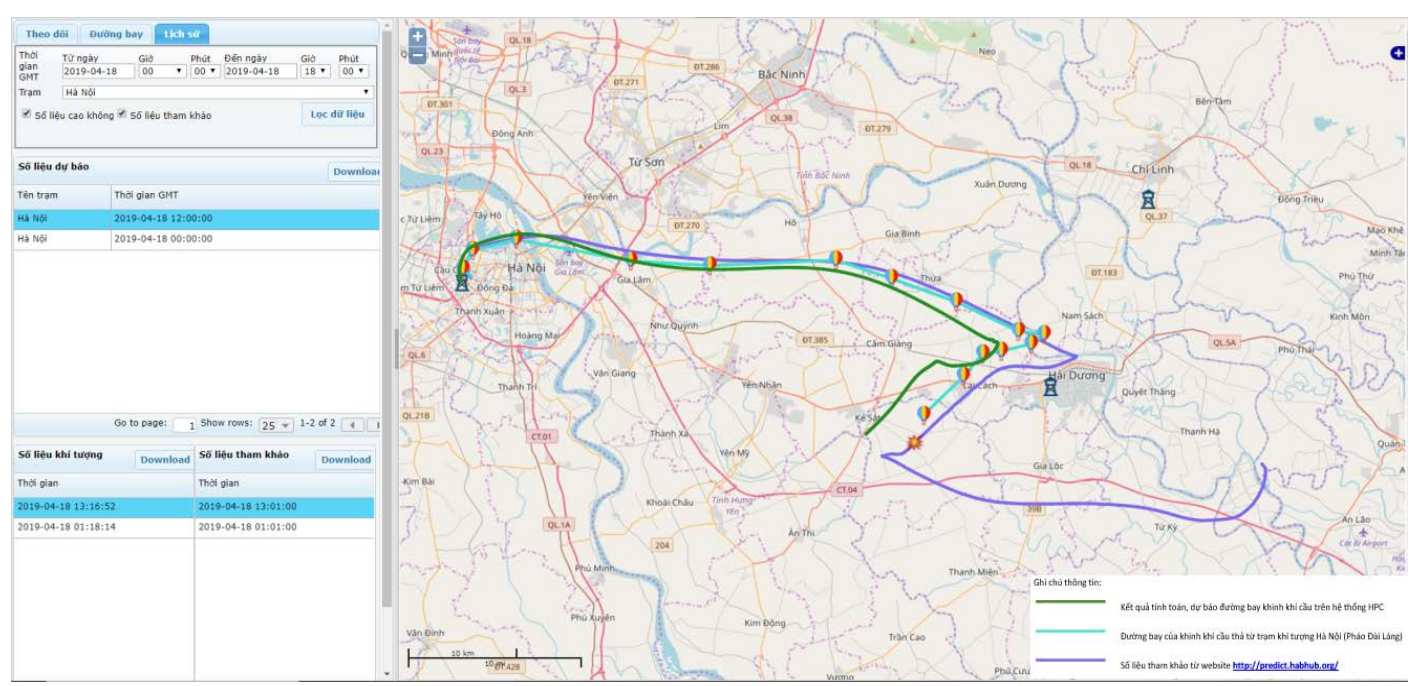

Hình 5. Số liệu dụ báo ngày 18/04/2019 phiên 12UTC. Kí hiệu tưong tụ hình 4.

Một số đánh giá thêm dựa vào đường bay của bóng cao không (kí hiệu là $\mathrm{KKC}$ ), quỹ đạo dự báo (kí hiệu là đường tính toán từ hệ thống HPC) và số liệu từ mô hình CUSF (lấy từ trang web http://predict.habhub.org) (hình 6) cho thấy từ bay được, quỹ đạo của bóng của cả 3 đều gần như trùng với nhau. Ở nửa quãng đường sau, kết quả tính toán dự báo trên hệ thống HPC cho di chuyển của bóng lệch về hướng Bắc so với quỹ điểm được thả đến một nửa quãng đường bóng đạo thực tế của bóng và của mô hình CUSF.

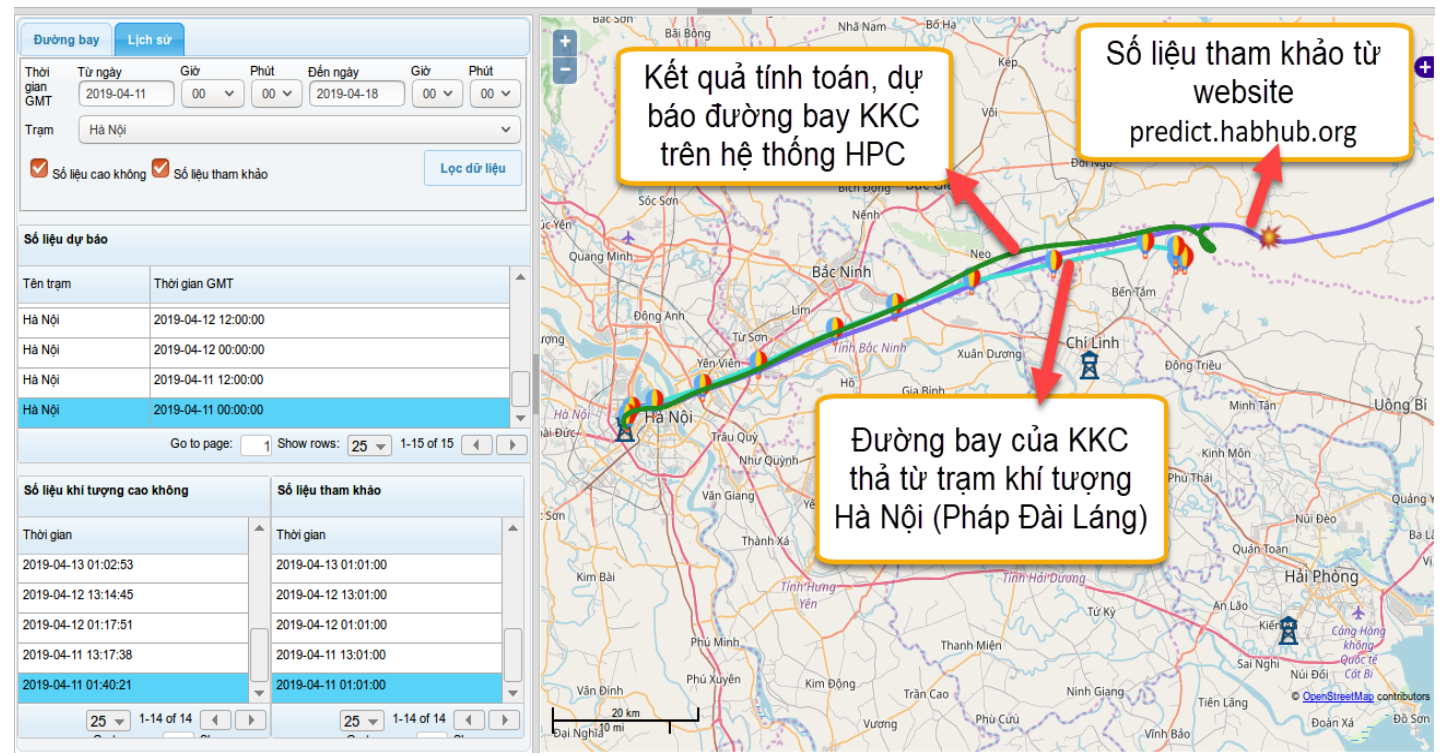

Hình 6. Số liệu dư báo ngày 11/04/2019 phiên 00UTC. Kí hiệu tưong tụ hình 4

Trong Bảng 2 đưa ra sai số trung bình (Mean Error) theo độ phân giải thời gian từng 10 phút tính từ thời điểm thả bóng từ $01 / 4 / 2019$ đến $30 / 4 / 2019$, các obs $00 \mathrm{z}$ và $12 \mathrm{z}$ (62 mẫu) cho thấy trong giai đoạn độ cao thấp (30 phút đầu), sai số khi sử dụng số liệu WRF-ARW thấp hơn so với sử dụng số liệu GFS (giữ cố định trong 1 tiếng do chỉ có số liệu 3 tiếng một) ứng với các mực thấp chịu ảnh hưởng của lớp biên khí quyển. Khi bóng lên cao, sai số giữa việc sử dụng GFS và WRF-ARW khác nhau không nhiều do tính chất ổn định của khí quyển trên cao. 
Bảng 2. Sai số của kinh độ, vĩ độ và độ cao trung bình theo độ phân giải thời gian 10 phút, dụ báo 1 tiếng, đơn vị $\mathrm{km}$, tù 01/4/2019 đến 30/4/2019, các obs $00 z$ và $12 z$

\begin{tabular}{ccccccc}
\hline $\begin{array}{c}\text { Thời gian } \\
\text { dự báo tính } \\
\text { từ lúc bắt } \\
\text { đầu thả } \\
\text { bóng }\end{array}$ & Lat_WRF & Lon_WRF & Height_WRF & Lat_GFS & Lon_GFS & Height_GFS \\
\hline+10 & 0.31 & 0.26 & 0.15 & 0.35 & 0.29 & 0.16 \\
+20 & 0.30 & 0.31 & 0.16 & 0.33 & 0.35 & 0.16 \\
+30 & 0.33 & 0.29 & 0.12 & 0.30 & 0.34 & 0.14 \\
+40 & 0.25 & 0.28 & 0.17 & 0.26 & 0.27 & 0.18 \\
+50 & 0.28 & 0.26 & 0.19 & 0.29 & 0.30 & 0.2 \\
+60 & 0.25 & 0.28 & 0.20 & 0.26 & 0.27 & 0.19 \\
\hline
\end{tabular}

\section{Kết luận}

Nghiên cứu trình bày một số kết quả thử nghiệm tính toán quỹ đạo bay (trajectory) của bóng thám không sử dụng sơ đồ sai phân trung tâm theo thời gian và trường gió chi tiết từ mô hình khí tượng khu vực WRF-ARW. Dự báo từ mô hình toàn cầu GFS chỉ có thể cung cấp với bước thời gian 3 tiếng một lần và tại các mực cơ bản, việc hạ quy mô bằng mô hình WRF-ARW cho phép cập nhật dự báo trường gió với bước thời gian từ 5-10 phút và chi tiết theo mực thẳng đứng đến độ cao $1 \mathrm{hPa}$ (độ cao nhất mà GFS cung cấp làm điều kiện biên). Các kết quả đã được so sánh thực tế với quỹ đạo của bóng thám không quan trắc khí tượng và từ dự báo của mô hình CUSF bước đầu cho thấy tính phù hợp của mô hình dự báo quỹ đạo trong nghiên cứu đưa ra. Trong mô hình CUSF đang sử dụng đầu vào (trường gió) từ mô hình GFS nên không chi tiết bằng việc sử dung trường gió dự báo mô hình WRF-ARW và một số phân tích đánh giá cho thấy tính phù hợp so với thực tế của quỹ đạo bóng trong nghiên cứu hơn so với kết quả từ mô hình CUSF. Ngoài hạn chế trong việc đưa ra các thông tin đánh giá sai số trường gió của $\mathrm{GFS}$ và WRF-ARW, nghiên cứu này là mới thử nghiệm mô phỏng quỹ đạo dựa trên trường gió của mô hình WRF-ARW và chưa tính đến sự chênh lệch áp suất của bóng và áp suất môi trường cũng như tốc độ thẳng đứng riêng của bóng để xác định thêm quá trình cân bằng động lực của bóng và dự báo việc dừng-nổ của bóng như trong mô hình CUSF. Các hệ thống mô phỏng động lực cân bằng bóng sẽ được đưa ra trong thử nghiệm tiếp theo. Việc kết quả dự báo quỹ đạo bóng phù hợp là cơ sở để xác định trước các vị trí bóng quan trắc cần thả tới, ví dụ cần quan trắc bổ sung trên khí quyển khu vực Vịnh Bắc Bộ, ứng với trường gió dự báo cho trước từ mô hình WRFARW có thể áp dụng tích phân ngược (backward) của mô hình dự báo quỹ đạo và xác định được vị trí cần thả bóng ban đầu để đạt được độ cao và vị trí theo thời gian định trước. Các nghiên cứu tới sẽ đánh giá chi tiết hơn về vấn đề dự báo backward ngược theo thời gian của mô hình dự báo quỹ đạo với bóng thám không và tính tới những đặc tính riêng biệt của từng loại bóng.

Lời cảm ơn: Bài báo mô tả một phần kết quả của Đề tài mã số VT-CN.04/17-20 thuộc Chuơng trình Khoa Học và Công Nghệ cấp quốc gia về Công nghệ vũ tru giai đoạn 2016-2020, Viện Hàn Lâm Khoa Học và Công Nghệ Việt Nam 


\section{Tài liệu tham khảo}

1. Hoàng Đức Cường và các cộng tác viên, (2011), Nghiên cưu ứng dụng mô hình WRF dụ báo thờ tiết và bão ở Việt Nam. Báo cáo tổng kết đề tài NCKH cấp Bộ TN\&MT.

2. Michalakes, J., Dudhia, J., Gill, D., Henderson, T., Klemp, J., Skamarock, W., Wang, W. (2005), The Weather Research and Forecast Model: Software Architecture and Performance, Proceedings of the Eleventh ECMWF Workshop on the Use of High Performance Computing in Meteorology, World Scientific, 156-168.

3. Yajima, N., Izutsu, N., Imamura, T., Abe, T. (2004), Launching Rockets from Ballons (Rockoons). Scientific Ballooning, Springer, 162. Doi:10.1007/978-0-387-09727-5. ISBN 978-0-38709725-1.

4. Skamarock, W.C., Klemp, J.B., Dudhia, J., Gill, D.O., Barker, D.M., Duda, M.G., Huang, X.Y., Wang, W., Powers, J.G. (2005), A description of the Advanced Research WRF Version 3, NCAR Tech. Note NCAR/TN-475+STR, pp. 113.

5. Stohl, A., Seibert, P. (1998), Accuracy of trajectories as determined from the conservation of meteorological tracers. Quarterly Journal of the Royal Meteorological Society, 124(549, Part A), 1465-1484.

6. Tozer, T.C., Grace, D. (2001), High-altitude platforms for wireless communications, Electronics \& Communication Engineering Journal, VI-2001.

7. Võ Văn Hòa và cộng tác viên (2010), Nghiên cứu phát triển hệ thống dư báo tổ hợp thời tiết hạn ngắn cho khu vưc Việt Nam. Thuyết minh đăng ký đề tài NCKH cấp Bộ, 17 tr.

8. Dư Đức Tiến, Hoàng Đức Cương, Mai Khánh Hưng, Hoàng Phúc Lâm (2019), Đánh giá tác động của việc sủ dụng tham số hoá đối lư trong dụ báo đợt mưa lón tháng 7 năm 2015 trên khu vục Bắc Bộ bằng mô hình phân giải cao. Tạp chí Khí tượng Thủy văn, 699, 1-8.

9. Trang thông tin của Đài khí tượng Cao không: http://data.amo.gov.vn/content/tkvt/list.asp

\section{USING HIGH RESOLUTION WIND FORECAST FROM WRF-ARW MODEL IN TRAJECTORY SIMULATION FOR THE ADDITIONAL UPPERAIR OBSERVATING \\ Pham Hong Quang', Du Duc Tien², Pham Hong Cong', Mai Khanh Hung ${ }^{2}$, Dang Dinh Quan ${ }^{2}$ \\ ${ }^{1}$ Centre for Informatics and Computing, Vietnam Academy of Science and Technology \\ ${ }^{2}$ National center of hydro-meteorological forecasting}

Abstract: The paper presents some results using the wind fields from the high resolution region model WRF-ARW as the input for trajectory simulation. The initial test results in April 2019 which were being compared both to real upper air balloon (from Aero Meteorological Observation of Vietnam) and the simulations of Cambridge University model (CUSF landing predictor version 2.5) shows the capabilities in using WRF-ARW model and trajectory model (backward mode) to help selecting the landing off positions of the meteorological upper air balloon (drop-oriented problems) which can provide more observations over the sea or mountainous areas and therefore can provide more information for data assimilation processes of meteorological models in near futures.

Keyword: $W R F-A R W$, trajectory model, upperair observation. 